\title{
A Single-Switch Soft-Switching Electronic Ballast With High Input Power Factor
}

\author{
Chang-Shiarn Lin \\ Power Electronics Laboratory \\ Departxnent of Electrical Engineering. \\ National Taiwan University \\ Taipei,Taiwan
}

Chern-Lin Chen

\begin{abstract}
Design and analysis of a new single-switch soit-switching class electronic ballast with high input power factor is presented. Design equations for the optimum operating condition are derived and complete computer analysis is performed. It is shown that low tuty cycle control of the class $\mathbb{E}$ ballast can reduce the voltage stress of the controlied switch. A 40-W florescent lamp ballast is inmplemented and the experimental recordings verify the amalytical insults.
\end{abstract}

\section{INTRODUCTION}

High-frequency slectronic ballasts have attracted much attention in recent years. Electronic ballasting for fluorescent lamps greatly improves efficacy, efficiency and compactness. Moreover with the gcal of alleviating problems of noises, line-voltage distortion, and enforcement of new hamonic reguiations on the rutility line, there is a growing need for electronic ballasts with high input power factor. For this purpose, an input current shaper, power factor corrector (PFC), can be used in the input stage in place of the usual diode rectifier followed by a bulk capacitor. This solution, however, may result in unacceptable cost for ballast applications.

Single switch high input power factor electronic ballasts have been proposed[1,2] to improve efficiency, reliability, size, and weight. The input current shaper and the output high-frequency inverter are combined into one stage. Only one active switch is used. Yet, the singleswitch ballast presented by Licitra, etc. [1] would dim when the input sinusoidal voltage crosses zero. Flickering of twice line frequency might appear. Deng and Cuk presented a family of class- $E$ ballasts [2]. Simple structure and high performance are achieved. However with fixed $50 \%$ duty cycle control, the maximum voltage stress on the controlled semiconductor switch is 3.56 times the peak $\mathrm{AC}$ input voltage $[3,4]$. This peak stress would reach $604 / 1108 \mathrm{~V}$ for $120 / 220 \mathrm{~V} \mathrm{AC}$ input.
In this paper, new single-switch sof-switching electronic ballast with high input power factor is presented. Low duty cycle control is proposed for this class $\mathrm{E}$ ballast to reduce the maximum switch voltage stress. Design equations for the optimum operating condition to facilitate sof switching are derived and complete compuner analysis is performed.

\section{CIRCUIT DESCRIPTION}

The proposed circuit topology is shown in Fig. 1. The basic functions of the sub-circuits are:

BD1 :bridge rectifier, converting line-frequency AC power into DC;

$\mathrm{L}_{\mathrm{f}} \mathrm{C}_{\mathbb{f}}$ :EMI filter, fillering high-frequency noises;

$\mathbf{L}_{1}-\mathbf{D}_{1}$ :current shaper, shaping the input current wave form;

$\mathrm{S}_{1}$ :controlled active switch, controlling charging/ discharging of $\mathrm{L}_{1}$;

$C_{1}-D_{2}$ :soft switching components, facilitating sof? switching of $\mathrm{S}_{1}$;

$\mathbf{C}_{\mathbf{2}}$ :energy storage capacitor, reducing output ripples;

Ts :transformer, isolating the lamp load from the source;

${ }_{\mathrm{L}_{\mathrm{r}}} \mathrm{C}_{\mathbf{r}}$ : :resonant tank, the correct load angle [5] for soff switching must under proper design of $\mathrm{L}_{\mathrm{r}}$ and $\mathrm{C}_{\mathrm{p}}$;

$\mathbb{C}_{\mathrm{S}}$ :start-up capacitor, preheating the lamp filament and starting up the lamp;

$\mathbb{R}_{\text {lamp }}$ :equivalent resistor of the lamp.

\section{ANALYSIS}

1) Equivalent circuit: For convenience, the ballast can be studied as the equivalent circuits shown in Fig. 2(a). $V_{D C}$ represents the rectified and filtered $D C$ voltage before

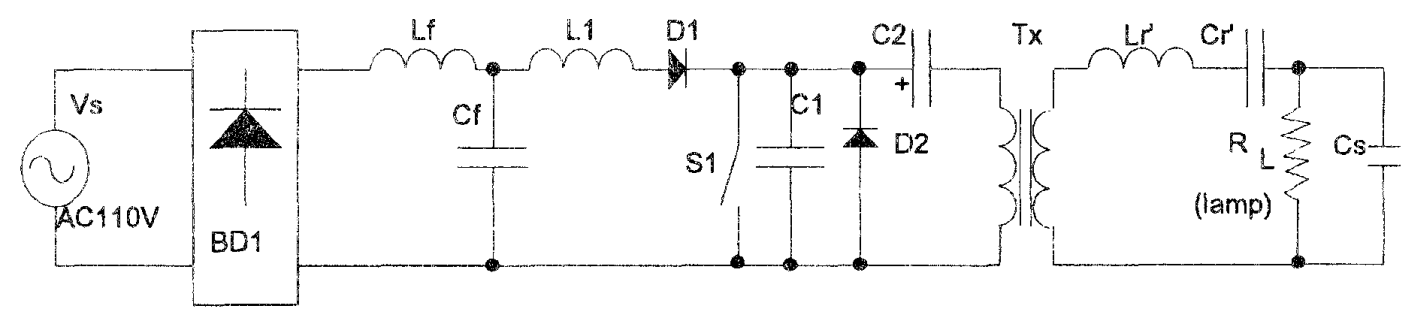

Fig. 1. The circuit diagram of a class $E$ electronic ballast 


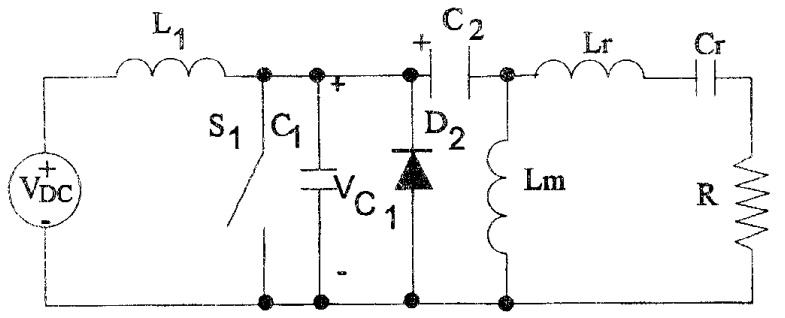

(a) Equivalent circuit.

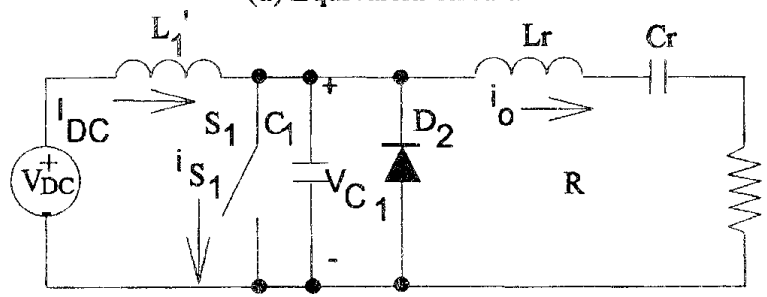

(b) Simplified equivalent circuit.

Fig. 2 The equivient circuit of the ballast.

$L_{1} . L_{m i n}$ is the magnetizing inductance of $T x$. Since the voltage source $V D C$ is shorted at high frequency analysis. To simplify analysis, we can make a dummy inductor $\mathrm{L}_{1}{ }^{\circ}$ which is equivalent to $L_{1}$ paralleling $L_{m}$ in the high frequency circuit model. $R$ represents the equivalent lamp resistance $\mathrm{R}_{\text {lamp }}$. The bulk capacitor $\mathrm{C}_{2}$ does not affect the high frequency operation, so it is shorted in the simplified equivalent circuit, Fig. 2(b). It is exactly a class $\mathrm{E}$ inverter. Before the analysis, the basic conditions must be mentioned:

1. Assume the main switch and all other components of the circuit are all ideal without any loss, so the efficiency of the converter is $100 \%$.

2. The load quality factor of the resonant tank must be high enough to generate a pure sinusoidal output current [6-8].

3. The damping ratio of the circuit is small enough so that the damping of the switching wave forms can be neglected.

4. The inductor $L_{1}^{\prime}$ need not to be infinity to act as a constant current source. The inverter can be operated with a finite dc-feed inductor $[9,10]$.

2) Circuit Operation: There are two stages of operations in the class $\mathrm{E}$ simplified equivalent circuit :

Stage 1.) $S_{l}$ is turned off, $L_{I}^{\prime}$ discharged: The equivalent circuit of this stage is depicted in Fig. 3(a). The supply current $I_{D C}$ and the output current $I_{0}$ pass

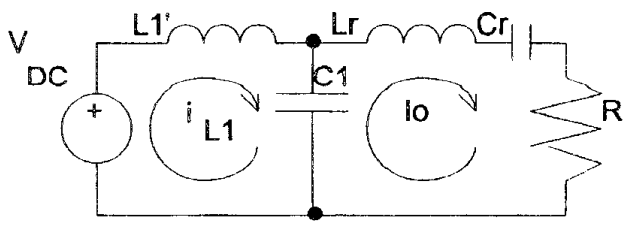

(a) stage $1-\mathrm{S} 1$ off

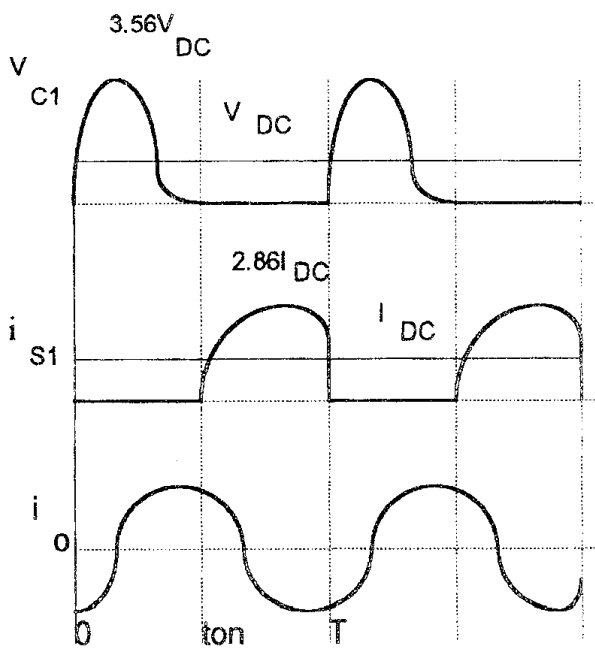

Fig. 4 The waveforms of the class $E$ inverter.

through $\mathrm{C}_{1}$. The voltage across $\mathrm{C}_{1}, \mathrm{~V}_{\mathrm{Cl}}$, forms a tilted sine wave as shown in Fig. 4.

Stage 2.) $S_{1}$ on, $L_{l}{ }^{9}$ charged: The equivalent circuit of this stage is depicted in Fig. 3(b). In this stage the supply current $I_{D C}$ and the output current $I_{0}$ pass through $S_{1}$. The current across $S_{1}$ form a tilted sine wave as shown in Fig. 4.

3) Circuit analysis: Two differential equations can be used to describe the wave form of $\mathrm{V}_{\mathrm{Cl}}$ and $i_{\mathrm{Ll}}$ in stage 1 :

$\left\{\begin{array}{l}\mathrm{V}_{\mathrm{C}_{1}}=\mathrm{V}_{\mathrm{DC}}-\mathrm{L}_{1}{ }^{\prime} \frac{{ }^{\mathrm{di}} \mathrm{L}_{1}{ }^{\prime}}{\mathrm{dt}} \\ \mathrm{dV}_{1} \frac{\mathrm{C}_{1}}{\mathrm{dt}}=\mathrm{i}_{\mathrm{L}_{1}}{ }^{--\mathrm{I}_{0}} \sin (\omega \mathrm{t}+\varphi)\end{array}\right.$

With the boundary conditions for $\mathrm{V}_{\mathrm{C} 1}$ :

$\left.\mathrm{V}_{\mathrm{C}_{1}}\right|_{t=0}=0,\left.\quad \mathrm{~V}_{\mathrm{C}_{1}}\right|_{t=t_{\text {on }}}=0,\left.\frac{\mathrm{dV}_{\mathrm{C}_{1}}}{\mathrm{dt}}\right|_{t=t_{\text {on }}}=0$

Where $\omega=2 \pi f_{S}$ and $f_{S}$ is the switching frequency. $\varphi$ is the legged load angle when the output current passes through the resonant network $\mathrm{Lr}-\mathrm{Cr}-\mathrm{R}$. ton $=(1-\mathrm{D}) \mathrm{T}, \mathrm{T}$ and $\mathrm{D}$ are

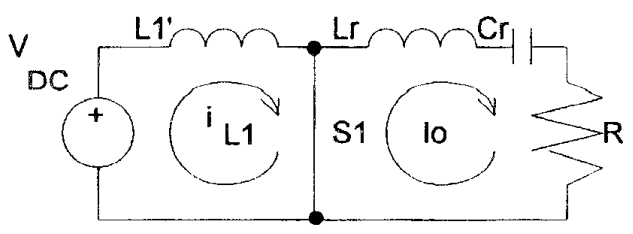

(b) stage 2 - S1 on

Fig. 3 Equivalent circuits representing circuit operations 
the switching period and duty cycle, respectively. The $\mathrm{V}_{\mathrm{Cl}}$ wave form can then be solved as:

$$
\begin{aligned}
& V_{C_{1}}(t)=k_{1} \sin \left(\omega_{1} t\right)+k_{1} \cos \left(\omega_{1} t\right)+ \\
& \frac{\omega}{C_{1}\left(\omega^{2}-\omega_{1}^{2}\right)} I_{0} \cos (\omega t+\varphi)+V_{D C}
\end{aligned}
$$

The load angle $\varphi$ can be found numerically from (4) when the duty cycle is not $50 \%$ :

$(1-D) \sin \left(\omega \mathrm{t}_{\text {on }}+\varphi\right)+\frac{1}{2 \pi}\left[\cos \left(\omega \mathrm{t}_{\text {on }}+\varphi\right)-\cos \varphi\right]=0$

The output current $I_{0}$ can be calculated by solving:

$$
I_{0} \sin \left(\omega t_{\text {on }}+\varphi\right)-\left(I_{D C}-\frac{D^{2} T V_{D C}}{2 L_{1}^{\prime}}\right)=0, I_{0} \geq 0
$$

The output lamp resistor $R$ can be determined from the assumption of input/output power equality, as a first-cut estimate.

$$
\mathrm{P}=\mathrm{V}_{\mathrm{DC}}{ }^{*} \mathrm{I}_{\mathrm{DC}}=\frac{\mathrm{V}_{\mathrm{O}} \mathrm{I}_{\mathrm{O}}}{2}=\frac{\mathrm{RU}_{\mathrm{O}}{ }^{2}}{2}
$$

$C_{1}$ can be found by observing no $D C$ voltage across $L_{1}^{\prime}$

$\frac{1}{T} \int_{0}^{t}$ on $V_{C_{1}} d t=V_{D C}$

Once the circuit parameter has been determined, the voltage stress of $s_{1}$ can be found by solving, the instant when the maximum $V_{C 1}$ occurs.

$$
\left.\frac{d V_{C_{1}}}{d t}\right|_{t=t_{\max }}=0, \quad 0<t_{V_{\max }}<t_{\text {on }}
$$

Then the peak voltage stress is derived:

$\mathrm{V}_{\mathrm{S}_{1 \max }}=\left.\mathrm{V}_{\mathrm{C}_{1}}\right|_{\mathrm{t}=\mathrm{t}_{\mathrm{V}_{\text {max }}}}$

In the second stage, the current passes through $\mathrm{S} 1$ can be mathematically expressed as:

$$
\begin{aligned}
\mathrm{i}_{S_{1}} & =\mathrm{i}_{L_{1^{\prime}}}-\mathrm{i}_{0} \\
& =I_{\mathbb{L}_{1}}\left(\mathrm{t}_{\text {on }}\right)+\frac{V_{D C}}{L_{1}{ }^{\prime}}\left(t-t_{\text {on }}\right)-I_{0} \sin (\omega t+\varphi)
\end{aligned}
$$

The instant when the maximum switch current occurs is obtained by solving:

$\left.\frac{d \mathrm{~s}_{1}}{\mathrm{dt}}\right|_{\mathrm{t}=\mathrm{t}_{\mathrm{i}_{\text {max }}}}=0 \quad \mathrm{ton}_{\text {on }}<\mathrm{t}_{\mathrm{i}_{\max }}<\mathrm{T}$

or the maximum current occur at $t=0$ when (11) has no solution. Thus the naximum current is:

$\mathrm{I}_{\mathrm{S}_{\text {max }}}=\left.\left.\mathrm{i}_{\mathrm{S}}\right|_{1}\right|_{\mathrm{t}=\mathrm{t}_{\mathrm{i}_{\max }}}$

Fig. 5 shows an electronic ballast design for $110 \mathrm{VAC}$ input. The switch stresses versus duty cycle $D$ from 0.5 to 0.2 when $L_{1}{ }^{\prime}$ is infinite and $0.9 \mathrm{mH}$, respectively. We can see that the low duty cycle operation of the circuit can reduce the voltage stress and increase the current stress. In low power electronic ballasts design, there is a slight voltage safety margin but a large current safety margin for the switch. For example, the voltage and current rating of $\operatorname{IRF} 740$ is $400 \mathrm{~V} / 5.5 \mathrm{~A}$. If the output power is $40 \mathrm{~W}$, usually the peak current of the switch is $1 \mathrm{~A}$, much lower than 5.5A. Thus in class $\mathrm{E}$ ballasts we can transfer the voltage stress to the current stress by low duty cycle operation.

\section{POWER FACTOR CORRE:CTION}

For single-stage electronic ballasts, a front-ended discontinuous inductor current mode (DICM) power factor correction is needed. The discontinuous inductor can bs considered as $\mathrm{L}_{1}$ in the class $\mathrm{E}$ electronic ballast in Fig. 1 . The inductor $L_{1}$ has a critical value when operating at the boundary of continuous and discontinuous mode:

$\mathrm{L}_{\mathrm{Cr}}=\frac{\mathrm{DTV}_{\mathrm{S}_{\mathrm{m}}}}{2 \mathrm{I}_{\mathrm{S}}}, \quad \mathrm{L}_{\mathrm{l}}<\mathrm{L}_{\mathrm{Cr}}$

The voltage conversion ratio:

$M=\frac{V_{\text {boost }}}{V_{S_{m}}}$

where $V_{s m}$ is the maximum value of input $A C$ voltage. $V_{\text {boost }}$ is the boost power factor corrector output $D C$ voltage. In this circuit $\mathrm{V}_{\text {boost }}$ is the DC component of $\mathrm{V}_{\mathrm{Cl}}$ in stage 1 .

$V_{\text {boost }}=\frac{1}{t_{\text {on }}} \int_{0}^{t_{\text {on }}} V_{C_{1}} d t=\frac{1}{1-D} V_{D C}$

then

$\mathrm{V}_{\mathrm{DC}}=\mathrm{M}(1-\mathrm{D}) \mathrm{V}_{\mathrm{S}_{\mathrm{m}}}$ 

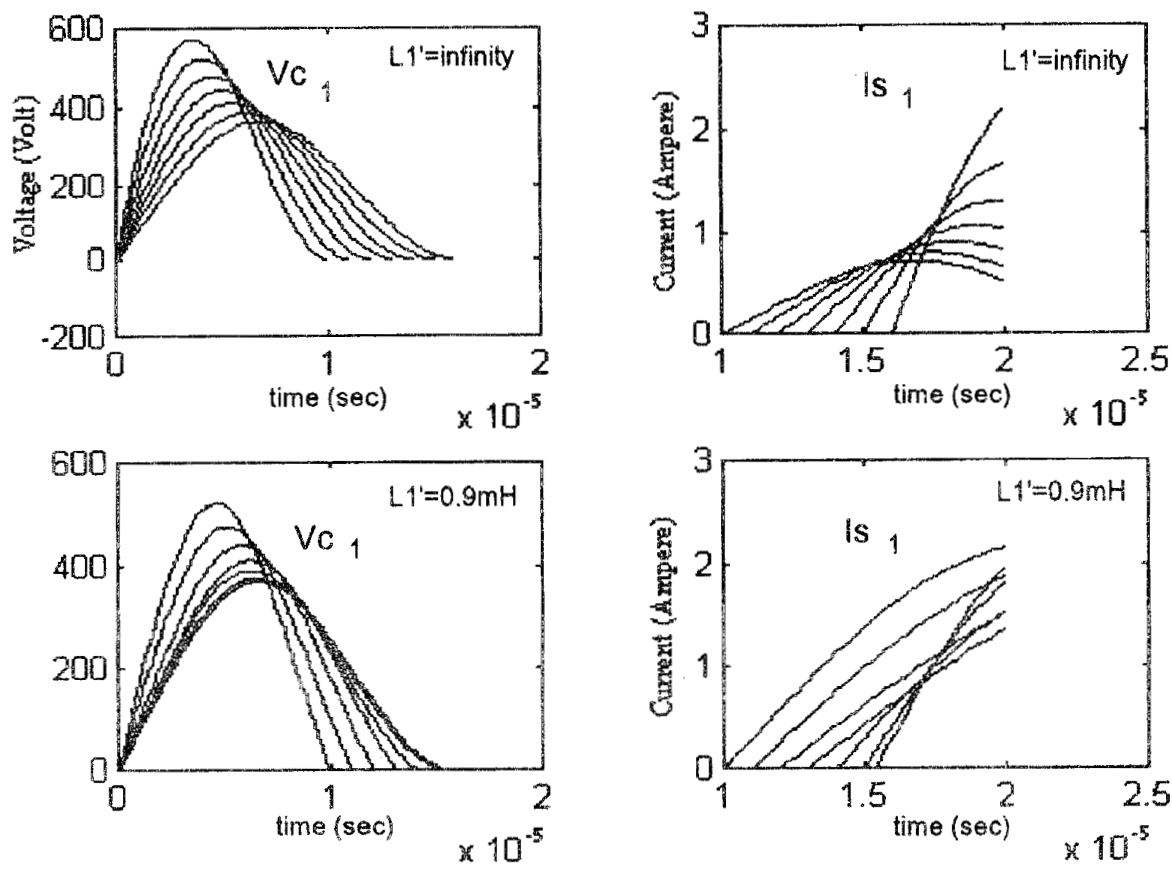

Fig. 5 The voltage and current waveforms of $\mathrm{S} 1$ versus D.

In Fig. $1 \mathrm{C}_{2}$ blocks the $\mathrm{DC}$ component of $\mathrm{V}_{\mathrm{Cl}}$, so

$\mathrm{V}_{\mathrm{C}_{2}}=\frac{1}{\mathrm{~T}} \int_{0}^{\mathrm{T}} \mathrm{V}_{\mathrm{C}_{1}} \mathrm{dt}=\mathrm{V}_{\mathrm{DC}}=\mathrm{M}(1-\mathrm{D}) \mathrm{V}_{\mathrm{S}_{\mathrm{m}}}$

$\mathrm{C}_{2}$ must be large enough to hold up the power while input power decrease. The minimum value of $\mathrm{V}_{\mathrm{Cl}}$ can be determined by:

$c_{2}=\frac{p}{\omega_{L} V_{C_{2}} \Delta V}$

where $\Delta V$ is the peak to peak ripple of $V_{C 2}$ and $\omega_{L}$ is the $\mathrm{AC}$ source angular frequency. Fig. 6 and Fig. 7 shows the ballast output current with large $C_{2}$ and small $C_{2}$, respectively. Obviously, a large $\mathrm{C}_{2}$ can avoid the twice line-frequency flickers which cause the low quality lighting and shorten lifetime of the lamps.

At the discontinuous operation, neglecting the high order terms, the approximate average input current can be expressed as:

$i_{S_{L}}=I_{S_{m}} \sin \left(\omega_{L} t\right) \frac{M D}{M-\mid \sin \left(\omega_{L} t\right)}$

where $I_{s m}$ is the maximum value of input current $I_{s}$. The plot of average input current versus duty cycle is shown in Fig. 8. The power factor varies with duty cycle is given in

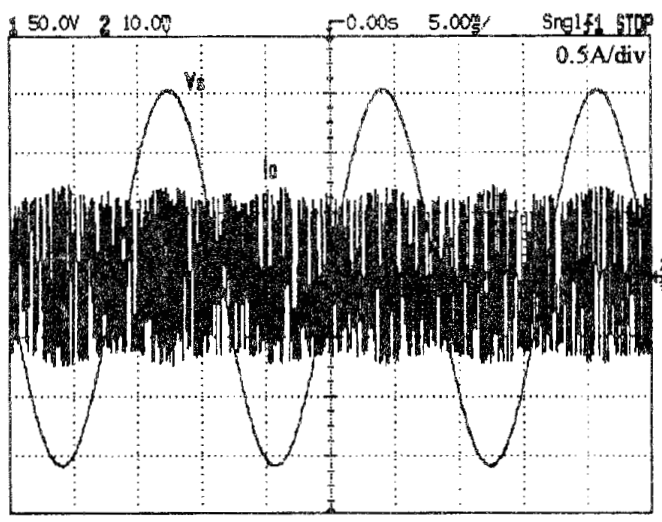

Fig. 6 The output current with large $\mathrm{C} 2$.

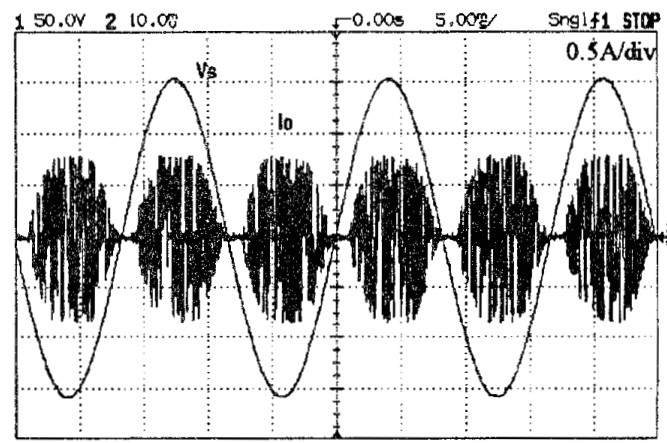

Fig. 7 Line-frequency flickers caused by small C2 
Fig. 9. The low duty cycle slightly deteriorates the power factor, but still higher than 0.95 .

\section{EXPERIMENTAL RESULTS}

A $40 \mathrm{~W}$ fluorescent lamp ballast adopting the proposed circuit is developed. Circuit parameters of the experimental ballast are:

$$
\begin{array}{ll}
\mathrm{L}_{\mathrm{l}}=0.9 \mathrm{mH}, & \mathrm{C}_{\mathrm{l}}=14.7 \mathrm{nF}, \\
\mathrm{L}_{\mathrm{m}}=2 \mathrm{mH}, & \mathrm{L}_{\mathrm{r}}=4 \mathrm{mH}, \\
\mathrm{C}_{\mathrm{r}}=100 \mathrm{nF}, & \mathrm{R}_{\mathrm{lamp}}=250 \Omega, \\
\mathrm{C}_{\mathrm{s}}=3.3 \mathrm{nF}, & \mathrm{C}_{2}=68 \mathrm{uF},
\end{array}
$$

Tx turn ratio $=1: 1.25, \quad \mathrm{Vs}=110 \mathrm{VAC}$,

$$
\mathrm{S}_{1}: \mathrm{IRF830}, \quad \mathrm{f}_{\mathrm{S}}=50 \mathrm{kCH} \text {, }
$$

$D=0.3$.

The recorded voltage and current wave forms of $S_{1}$ are shown in Fig. 10(a). The discontinuous current wave form of inductor $L_{1}$ is shown in Fig. 10(b). The input and output voltage/current wave forms of the ballast are shown in Fig. $10(c)$ and $10(d)$, respectively. The maximum voltage stress for $S_{1}$ is about $400 \mathrm{~V}$. The measured input power factor is 0.97 .

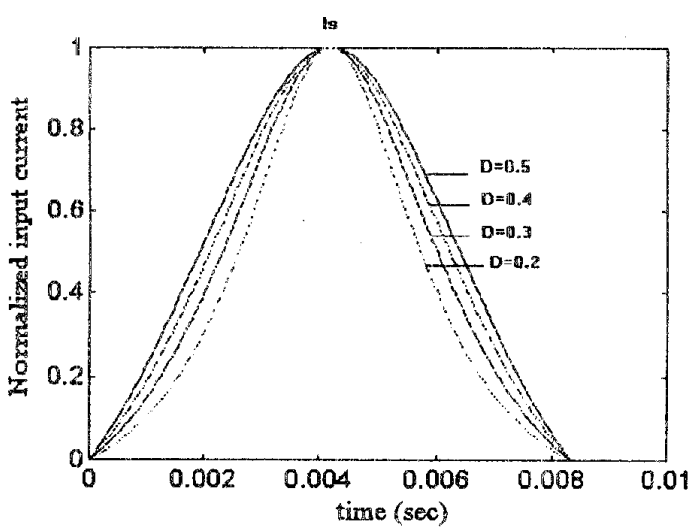

Fig. 8. The input current versus $D$

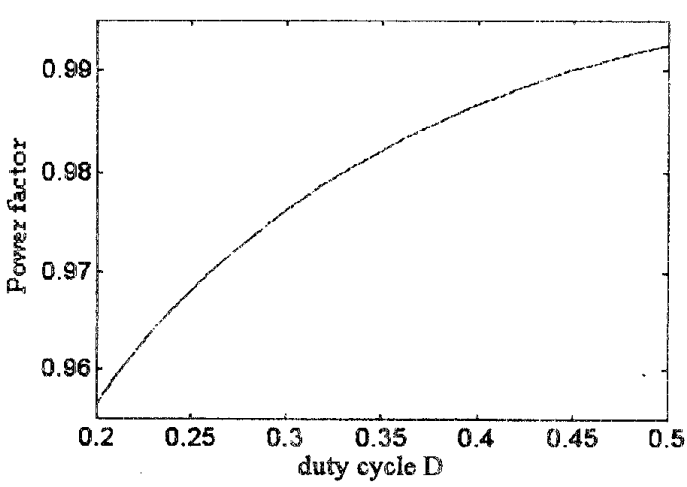

Fig. 9. The power factor versus D

\section{CONCLUSIONS}

A single-stage single-switch high-power-factor electronic ballast is presented. It has no line flickers by adding the energy storage element. The major problem of class $E$ type ballasts is the high voltage stress. The problem can be relieved by the low duty cycle operation of the switch. While the duty cycle is not 0.5 , Circuit parameters are difficult to be determined due to nonlinearity of the circuit operations. This paper proposes the design equations and rules to determine the circuit parameter:s.

\section{REFERENCES}

[1] C. Licitra, L. Malesami, G. Spiazzi, P. Tenti, and A. Testa, "Single-Ended Sof-switching Electronic Ballast with Unity Power Factor", IEEE Transactions on Industry Applications, Vol. 29, NO 2., pp. 382-388, March/April 1993.

[2] E. Deng and S. Cuk, "Single Switch, Unuty Power Factor, Lamp Ballasts", IEEE Applied Power Electronics Conference 1995, pp. 670-676.

[3] G. Lutteke and H. C. Raets, "High Voltage High Frequency Class E Converter Suitable for Miniaturization", IEEE Transaction on Power Electronics, Vol. PE-1, No. 4, pp. 193-199, October 1986.

[4] G. Lutteke and H. C. Raets, "220-V Mains 500-kHz Class E Converter Using a BiMos", IEEE Transaction on Power Electronics, Vol. PE-2, No. 3, pp. 186-193, July 1987.

[5] N. O. Sokal, A. D. Sokal, "Class E-A New Class of High-Efficiency Tuned Single-ended Switching Power Amplifiers" , IEEE Joumal of Solid-State Circuits, Vol. SC-10, NO. 3, pp. 168-176, June 1975.

[6] F. H. Raab, "Ideal Operation of the Class E Tuned Power Amplifier" , IEEE Transactions on Circuits and Systems, Vol. CAS-24, No. 12, pp. 725-735, December 1977.

[7] F. H. Raab, "Effects of Circuit Variations on the Class E Tuned Power Amplifier" , IEEE, Journal of SolidState Circuits, Vol. SC-13, NO. 2, pp. 239-247, April 1978.

[8] M. K. Kazimierczuk and K. Puczko, "Exact Analysis of Class $E$ Tuned Power Amplifier at any $Q$ and Switch Duty Cycle" , IEEE Transaction on Circuits and System, Vol. CAS-34, No. 2, pp. 149-159, Feburary 1987.

[9] R. Zulinsky and J. W. Steadman, "Class E Power Amplifiers and Frequency Multipliers with Finite DC-Feed Inductance", IEEE Transaction on Circuits and Systems, Vol. CAS-34, No. 9, pp. 1074-1087. September 1987.

[10] R. Zulinsky, "A High-Efficiency Self-Regulated Class E Power Inverter/ Converter ", IEEE Transaction on Industrial Electronics, Vol. IE-33, No. 3, pp. 340342, August 1986. 


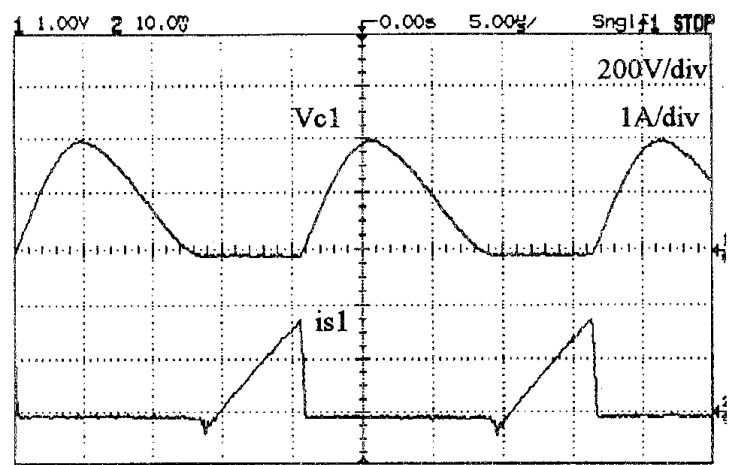

Fig. 10(a) The voltage and current waveform of S1.

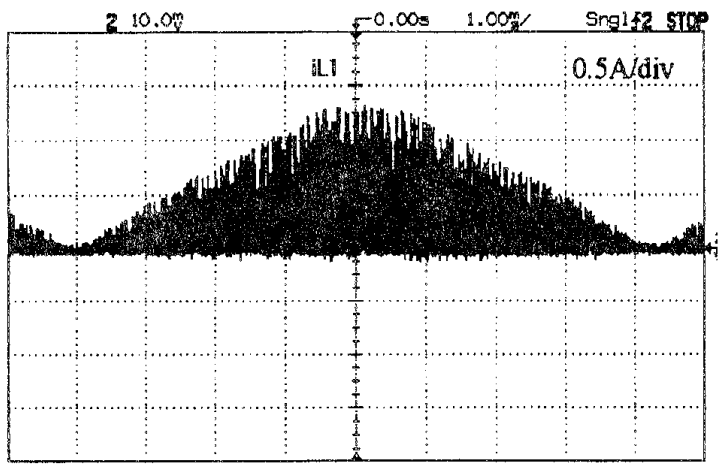

Fig. 10(b) The discontinuous current of $\mathrm{Ll}$.

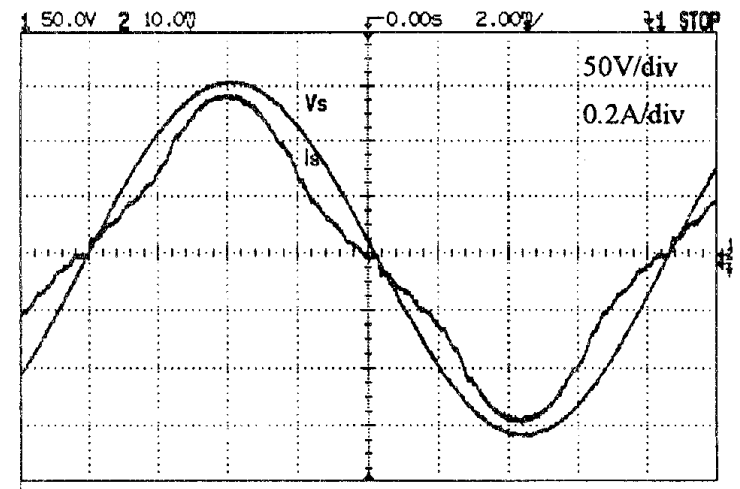

Fig. 10(c) The input voltage and current of the ballast.

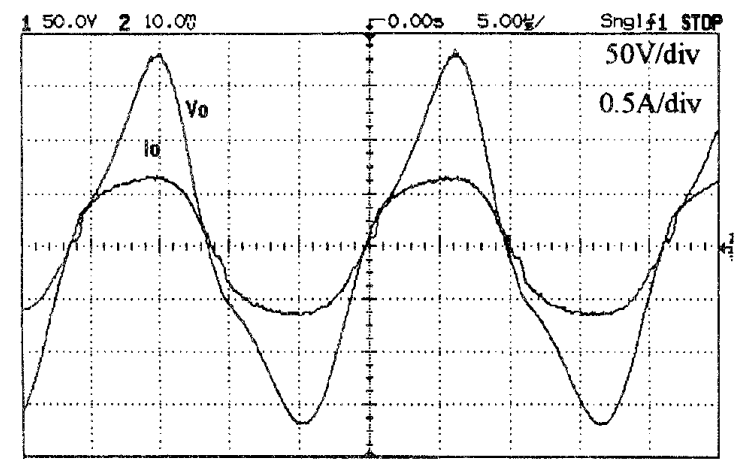

Fig. 10(d) The output voltage and current of the ballast. 